\title{
Erratum
}

\section{Erratum to "Unilateral Aplasia versus Bilateral Aplasia of the Vertebral Artery: A Review of Associated Abnormalities"}

\author{
L. Vasovićc ${ }^{1},{ }^{1}$ M. Trandafilović, ${ }^{1}$ S. Vlajković, ${ }^{1}$ G. Djordjević, ${ }^{2}$ \\ M. Daković-Bjelaković, ${ }^{1}$ and M. Pavlović ${ }^{1}$ \\ ${ }^{1}$ Department of Anatomy, Faculty of Medicine, University of Niš, 81 Blvd. Dr. Zoran Djindjić, 18000 Niš, Serbia \\ ${ }^{2}$ Health Center Niš, 15 Vojvode Tankosića St., 18000 Niš, Serbia \\ Correspondence should be addressed to L. Vasović; likica@medfak.ni.ac.rs
}

Received 14 January 2018; Accepted 16 January 2018; Published 21 February 2018

Copyright (C) 2018 L. Vasović et al. This is an open access article distributed under the Creative Commons Attribution License, which permits unrestricted use, distribution, and reproduction in any medium, provided the original work is properly cited.

In the article titled "Unilateral Aplasia versus Bilateral Aplasia of the Vertebral Artery: A Review of Associated Abnormalities" [1], there was an error in reference [80], which should be corrected as follows.

O. Yeniceri, N. Cullu, M. Deveer and R. M. Kilinc, "Persistent trigeminal artery anomaly with concomitant basilar artery hypoplasia," Austin Journal of Radiology, vol. 2, no. 2, p. 1014, 2015.

\section{References}

[1] L. Vasović, M. Trandafilović, S. Vlajković, G. Djordjević, M. Daković-Bjelaković, and M. Pavlović, "Unilateral Aplasia versus Bilateral Aplasia of the Vertebral Artery: A Review of Associated Abnormalities," BioMed Research International, vol. 2017, Article ID 7238672, 2017. 


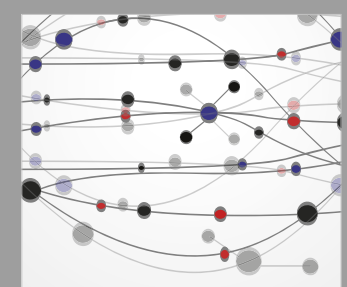

The Scientific World Journal
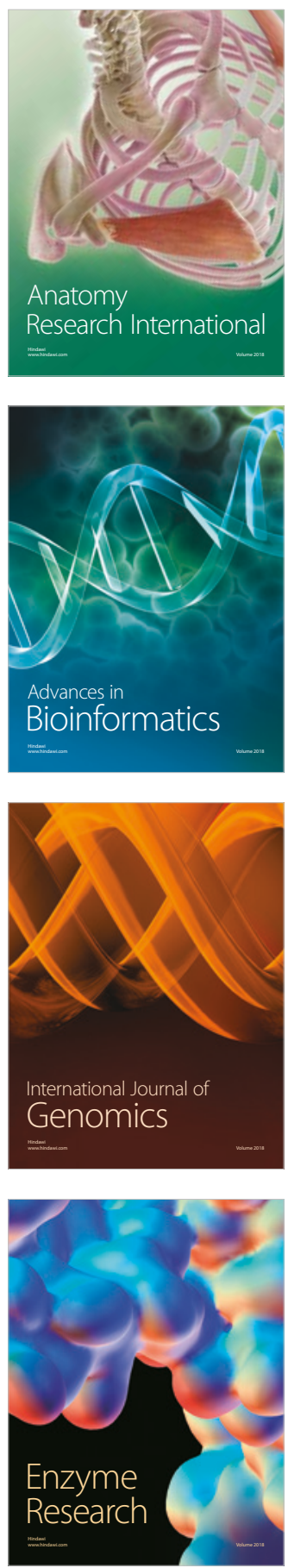
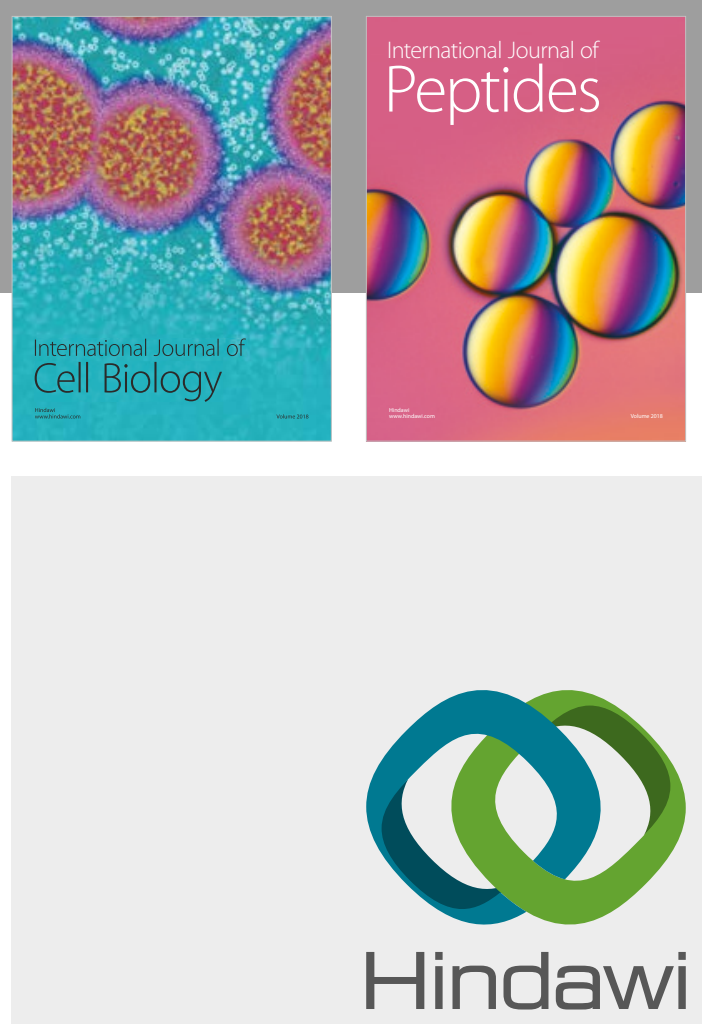

Submit your manuscripts at

www.hindawi.com
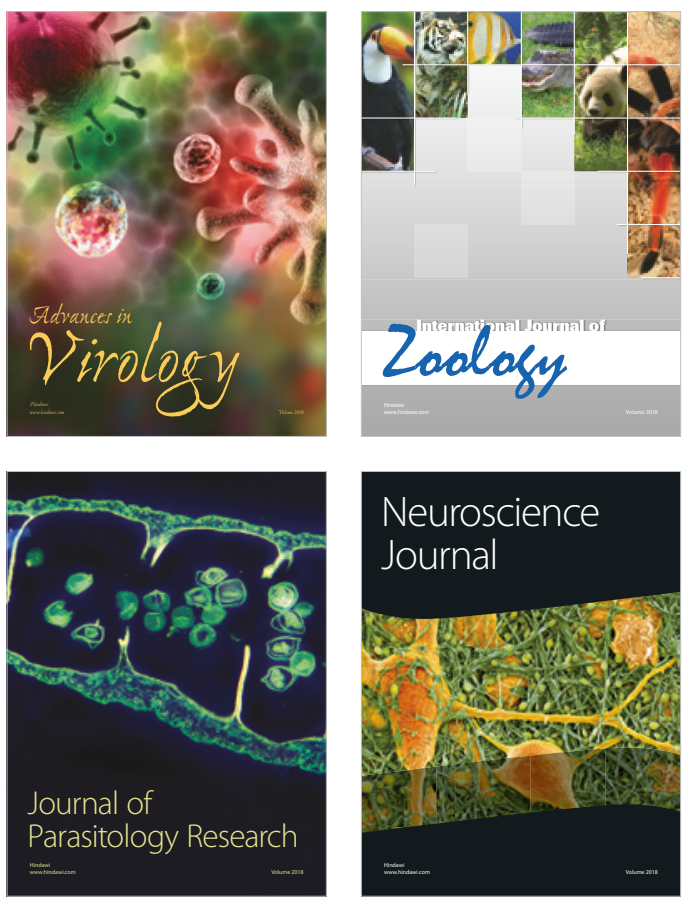
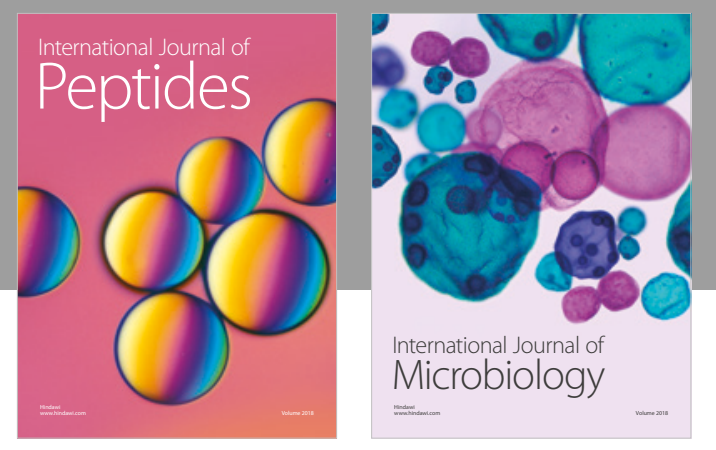

nternational Journal of Microbiology
Journal of
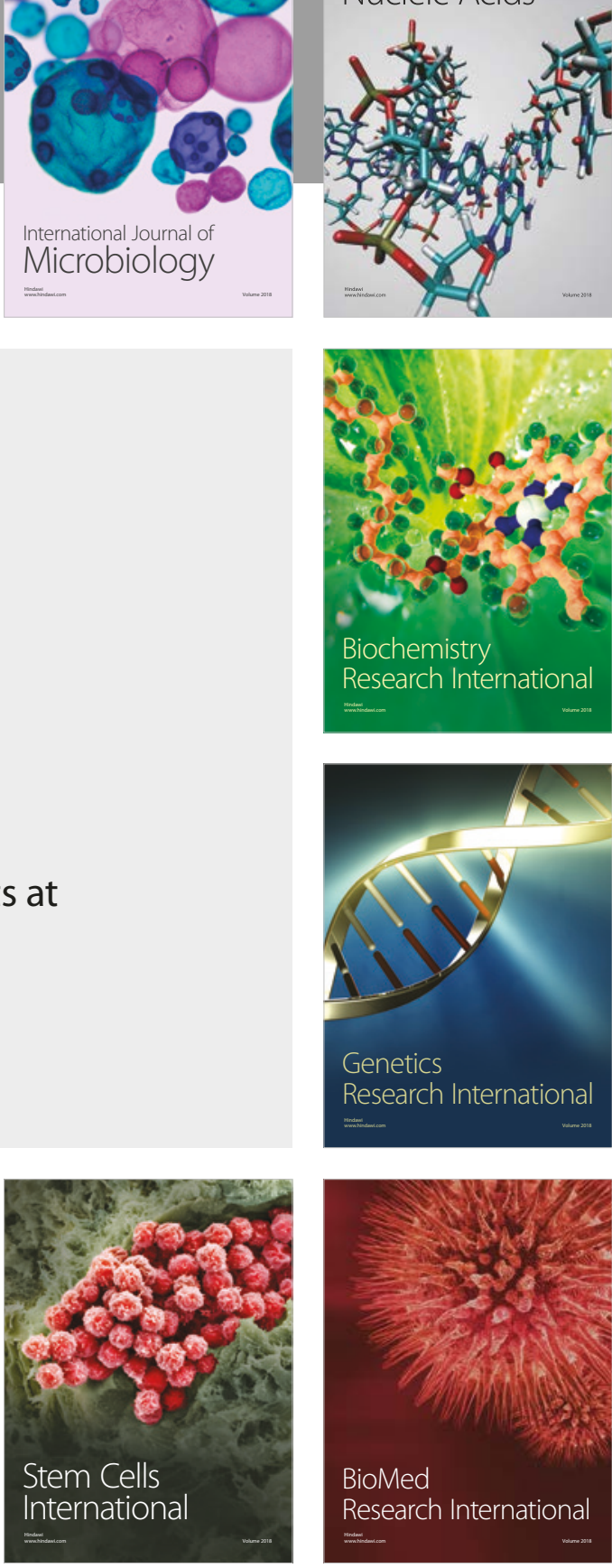
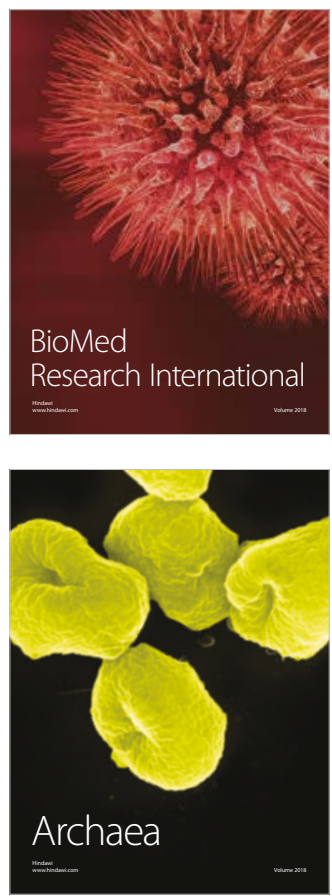